\title{
A selective LC-MS/MS method for simultaneous quantification of Artemether, Lumefantrine and their principle metabolites in human plasma
}

\author{
MARTIN O. ONGAS' ${ }^{1}$, ELIZABETH JUMA²*, CAROLINE G KIRIMI'1, FLORENCE OLO01, \\ GILBERT KOKWAR01, 5, RASHID AMAN 1 , 4, BERNHARDS R. OGUTU1, 2
}

${ }^{1}$ Center for Research in Therapeutic Sciences, Strathmore University, Nairobi, Kenya ${ }^{2}$ Centre for Clinical Research, Kenya Medical Research Institute -Nairobi, Kenya

${ }^{3}$ Consortium for National Health Research (CNHR), Kenya

${ }^{4}$ African Centre for Clinical Trials (ACCT), Kenya

${ }^{5}$ Institute of Healthcare Management, Strathmore University, Kenya

*(jumaelizabeth@yahoo.com)

This journal is licensed under a Creative Commons Attribution-NonCommercial 4.0 International License (CC-BY-NC).

Articles can be read and shared for noncommercial purposes under the following conditions:

- BY: Attribution must be given to the original source (Attribution)

- NC: Works may not be used for commercial purposes (Noncommercial)

This license lets others remix, tweak, and build upon your work non-commercially, and although their new works must also acknowledge you and be non-commercial, they don't have to license their derivative works on the same terms. License Deed Link: http://creativecommons.org/licenses/by-nc/4.0/

Legal Code Link: http://creativecommons.org/licenses/by-nc/4.0/legalcode

$A B C$ Research Alert uses the CC BY-NC to protect the author's work from misuse.

\section{Abstrac}

We have developed and validated a sensitive, selective and reproducible reversed-phase high-performance liquid chromatography method coupled with electrospray ionization mass spectrometry (HPLC-ESI-MS/MS) for the simultaneous quantitation of artemether (ART), dihydroartemisinin (DHA), lumefantrine (LUM) and desbutyl-lumefantrine (DBL) in human plasma. Mefloquine was used as an internal standard (IS). The analytes were extracted by protein precipitation procedure and separated on a reversed-phase Zorbax SB-Ciano column with a mobile phase composed of acetonitrile and $20 \mathrm{mM}$ aqueous ammonium formate containing $0.5 \%$ $(\mathrm{v} / \mathrm{v})$ formic acid. Multiple reaction monitoring was performed in the positive ion mode using the transitions $m / z \quad 316.3 \rightarrow m / z$ 163.1 (ART), $m / z$ 302.3 $\rightarrow m / z$ 163.1 (DHA), $m / z$ 530.3 $\rightarrow m / z$ 512.2. (LUM), $m / z \quad 472.2 \rightarrow m / z \quad 454.1$ (DBL) and $m / z$ 379.1 $\rightarrow m / z$ 361.1(MQ) to quantify the drugs. Calibration curves in spiked plasma were linear $\left(r^{2} \geq 0.9992\right)$ over the range of $5-1500 \mathrm{ng} / \mathrm{mL}$ for ART/ DHA and 5-5,000 ng/mL for LUM/DBL. The lower limit of quantitation (LLOQ) was $10 \mathrm{ng} / \mathrm{mL}$ ART/ DHA and $5 \mathrm{ng} / \mathrm{mL}$ for LUM/ DBL. The mean R.S.D. values for the intra-run precision were $2.2 \%, 3.8 \%, 1.9 \%$ and $4.7 \%$ and for the inter-run precision were $3.2 \%, 3.6 \%, 4.4 \%$ and $3.5 \%$ for ART, DHA, LUM and DBL, respectively. The mean percentage recovery values were $93.2 \%$, 98.5\%, 97.1\% and 99.4\% for ART, DHA, LUM and DBL, respectively. No matrix effect was detected for all the analytes and the IS. The validated method was successfully applied to determine the plasma concentrations of ART, DHA, LUM and DBL in pregnant and non-pregnant women volunteers in a multiple-dose pharmacokinetics study over the course of 336 hours.

Keywords

Artemether; Lumefantrine; Metabolites; LC-MS/MS; Pharmacokinetics; Human plasma. 


\section{INTRODUCTION}

Plasmodium falciparum has always developed widespread resistance to widely deployed antimalarial drugs requiring close monitoring of their efficacy (Martensson A. et al., 2005). The World Health Organization currently recommends artemisinin-based combination therapy (ACT), a combination of artemisinin derivative and another structurally-unrelated and slowly eliminated antimalarial for treatment of uncomplicated malaria (Global report 2010).

Artemether (ART) $20 \mathrm{mg}$ and lumefantrine (LUM) $120 \mathrm{mg}$ (Figure 1) is the most common ACT used in malaria endemic Africa (Omari A. et al., 2004). Whereas dihydroartemisinin (DHA) and desbutyl-lumefantrine (DBL) have been reported as active metabolites of ART and LUM respectively, with abilities to influence AL's treatment outcomes (Mugoyela, and Omary, 2011), no method has been validated to quantitate these drugs simultaneously. A quantitative assessment of ART, DHA, LUM and DBL in plasma in the course of AL treatment is essential in order to evaluate the bioavailability and pharmacokinetics of these co-formulated antimalarial compounds and how their potent metabolites influence treatment outcome. Previous studies have suggested that the area under the plasma Lumefantrine concentration-time curve was the principal determinant of curing malaria (Ezzet F. et al., 2000), and artemether formulations with a high bioavailability are considerably important to their rapid clinical efficacy (Karbwang J. et al., 1997).

Many methods have been reported for quantitation of either artemether (Navaratnam V. et al., 1995; Sandrenan N. et al., 1997; Souppart C. et al., 2002; Shi B. et al., 2006) or lumefantrine (Mansor M. et al., 1996; Zeng M. et al., 1996; Lindegårdh N. et al., 2005; Annerberg A. et al., 2005; Ashley A. et al., Wahajuddin, et al., 2009) in human plasma. Mc Gready et al., 2006 evaluated the pharmacokinetics of both drugs in pregnant women; however, the ART and LUM analysis were carried out separately. César et al., 2008 developed an LC-UV method for the simultaneous quantitation of artemether and lumefantrine in fixed-dose combination tablets. Nevertheless, ultraviolet detection is not adequate for ART quantitation in a biological matrix due to its low sensitivity and selectivity. Hodel et al., 2009 developed an HPLC-ESI-MS/MS method for the quantitation of 14 antimalarial drugs in human plasma, including ART and LUM. However, the method developed in our study involves a shorter sample processing time; absence of the drying and sample reconstitution with a shorter chromatographic run time. In addition, this is the first report providing simultaneous quantitation of ART, LUM and their metabolites with a pharmacokinetics application. This follows on César et al's simultaneous quantitation of ART and LUM.

In this study, we report an HPLC-ESI-MS/MS method for simultaneous quantitation of ART and LUM with their principle metabolites in human plasma. The method was successfully applied in a pharmacokinetic study of AL in pregnant and non-pregnant women who received a fixed- dose combination tablets during the course of their treatment for uncomplicated malaria. 


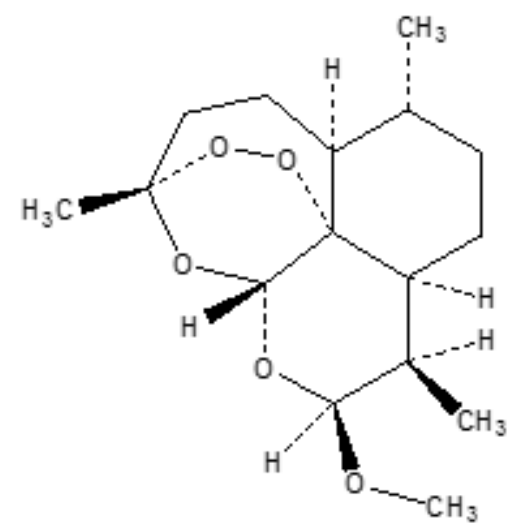

Artemether $298 \mathrm{~g} / \mathrm{mol}$

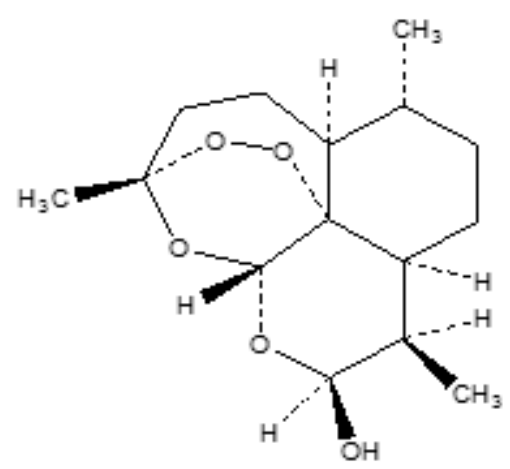

Dihydroartemisinin $284 \mathrm{~g} / \mathrm{mol}$<smiles>C[C@@]1([C](O)c2cc(C(F)(F)F)nc3c(C(F)(F)F)cccc23)CCCCN1</smiles>

Mefloquine $378 \mathrm{~g} / \mathrm{mol}$ (IS)<smiles>CCCCN(CCCC)CC(O)c1cc(Cl)cc2c1-c1ccc(Cl)cc1/C2=C\c1ccc(Cl)cc1</smiles>

Lumefantrine $529 \mathrm{~g} / \mathrm{mol}$<smiles>CCCCNCC(O)c1cc(Cl)cc2c1-c1ccc(Cl)cc1/C2=C/c1ccc(Cl)cc1</smiles>

Desbutyl-lumefantrine $472 \mathrm{~g} / \mathrm{mol}$

Figure 1. Chemical structures and molar masses of ART, LUM, DHA, BDL and Mefloquine (MQ), IS

\section{METHODOLOGY}

\section{Chemicals and reagents}

ART, LUM and MQ (IS) reference standards were purchased from United States Pharmacopeia (Rockville, USA), Dihydroartemisinin and Desbutyl-lumefantrine reference standards were 
kindly donated by the National Quality Control Laboratory (Nairobi, Kenya). Coartem ${ }^{\circledR}$ tablets were purchased from Novartis (Basel, Switzerland), deionized water was prepared using a Smart2 Pure ${ }^{\mathrm{TM}}$ water purification system (Thermo-scientific, Niederelbert, Germany). Blank human plasma with Li-heparin for the preparation of calibrators and quality controls was obtained from Kenya Medical Research Institute, Centre for Clinical Research (Nairobi, Kenya). Acetonitrile (HPLC), methanol (HPLC) and formic acid (analytical grade) were purchased from Sigma Aldrich (St Louis, MO, USA). Glacial acetic acid HiperSolv ${ }^{\circledR}$ grade was from BDH (Polle, UK) and ammonium formate, analytical grade (Fisher Scientific, UK).

\section{Instrumentation and analytical conditions}

The separation and quantitation of ART, LUM and metabolites were carried out on an Agilent technology HPLC-ESI-MS/MS system (Santa Clara, CA, USA), composed of a $1260 \mu$ binary pump, 1260 auto sampler and 1260 thermosetting column compartment (TCC) and an Agilent technology 6410 triple quadrupole mass spectrometer, equipped with an electrospray ion source. LC separation was performed on a Zorbax Eclipse XDB-CN (75mm x $4.6 \mathrm{~mm}$ I.D; $3.5 \mu \mathrm{m}$ particle size) from Agilent (Santa Clara, CA, USA) with a similar Zorbax RRHD security guard column $(5 \mathrm{~mm} \times 4.6 \mathrm{~mm}, 3.5 \mu \mathrm{m})$ maintained at $30{ }^{\circ} \mathrm{C}$. The mobile phase consisted of (A) $0.5 \%$ formic acid in $20 \mathrm{mM}$ aqueous ammonium formate and (B) $0.5 \%$ formic acid in acetonitrile.

A linear gradient elution was used to deliver the mobile phase, $60 \%$ acetonitrile (solvent B) at time $0 \mathrm{~min}$, and $75 \%$ from $2 \mathrm{~min}$, to $5 \mathrm{~min}$, and back to $60 \%$ from $6 \mathrm{~min}$ to $8 \mathrm{~min}$, (re-equilibration step). The flow rate was set at $0.5 \mathrm{~mL} / \mathrm{min}$, the autosampler was conditioned at $18{ }^{\circ} \mathrm{C}$, an injection volume of $20 \mu \mathrm{L}$ was used to optimize the drug signals and for analysis. Mass spectrometric detection was operated using electrospray ionization in the positive mode. Nitrogen was used as the nebulizing, desolvation and collision gas $\left(1.4 \times 10^{-3}\right.$ to $1.6 \times 10^{-3}$ mbar). The ion source parameters were: capillary $3.5 \mathrm{kV}$, exit potential $5 \mathrm{~V}$, RF lens $0.5 \mathrm{~V}$, source temperature was $100{ }^{\circ} \mathrm{C}$ and desolvation temperature $250{ }^{\circ} \mathrm{C}$. Multiple reaction monitoring (MRM) was employed for the data acquisition. The precursor ions of artemether and DHA were the ammonium adduct $\left[\mathrm{M}+\mathrm{NH}_{4}\right]^{+}$and the protonated molecular ion $[\mathrm{M}+\mathrm{H}]^{+}$ was the precursor ion of AL and DBL. The MRM was employed for data acquisition, analytical parameters optimized for the compounds were declustering potentials (DP) and collision energies (CE) (Table 1), the scan dwell time was set at $500 \mathrm{~ms}$ for each channel. Data acquisition and analysis were accomplished with Mass Hunter software (version A.02.00; Agilent Technologies).

\begin{tabular}{cccccc}
\hline Compound & $\begin{array}{c}\text { Precursor } \\
\text { Ion }\end{array}$ & $\begin{array}{c}\text { MRM }(\mathbf{Q} / \mathbf{Q 3}) \\
(\mathbf{a m u})\end{array}$ & $\begin{array}{c}\text { Dwell time } \\
(\mathrm{ms})\end{array}$ & $\begin{array}{c}\text { DP } \\
(\mathrm{V})\end{array}$ & $\begin{array}{c}\text { CE } \\
(\mathrm{eV})\end{array}$ \\
\hline ART & {$\left[\mathrm{M}+\mathrm{NH}_{4}\right]^{+}$} & $316.3 \rightarrow 163.1$ & 500 & 92 & 10 \\
DHA & {$\left[\mathrm{M}+\mathrm{NH}_{4}\right]^{+}$} & $302.3 \rightarrow 163.1$ & 500 & 90 & 10 \\
LUM & {$[\mathrm{M}+\mathrm{H}]^{+}$} & $530.3 \rightarrow 512.2$ & 500 & 150 & 30 \\
DBL & {$[\mathrm{M}+\mathrm{H}]^{+}$} & $472.2 \rightarrow 454.1$ & 500 & 110 & 18 \\
MQ & {$[\mathrm{M}+\mathrm{H}]^{+}$} & $379.1 \rightarrow 361.1$ & 500 & 60 & 30 \\
\hline
\end{tabular}

Table 1. Compound optimization parameters for artemether (ART), dihydroartemisinin (DHA), lumefantrine (LUM), desbutyl-lumefantrine (DBL) and mefloquine (MQ) and MRM transitions. 


\section{Preparation of standard solutions}

Stock solutions of ART, DHA and MQ $(1 \mathrm{mg} / \mathrm{mL})$ were prepared by dissolving the accurately weighed reference substances in methanol. LUM and DBL stock solutions $(1000 \mu \mathrm{g} / \mathrm{mL})$ were prepared in a similar way using methanol and glacial acetic acid (100:2) as a solvent. The working solution of MQ (IS) was prepared by diluting the stock solution with methanol to a final concentration of $10 \mu \mathrm{g} / \mathrm{mL}$. All of the stock solutions were prepared and stored in amber glass vials at nominal $20^{\circ} \mathrm{C}$ till use.

\section{Preparation of calibration and $Q C$ samples}

The working solutions containing both ART /DHA and LUM/ DBL were prepared using serial dilutions of the stock solutions with methanol and water $(50: 50, \mathrm{v} / \mathrm{v})$. Nine calibration samples were prepared by spiking the appropriate amounts of these working solutions into blank plasma obtained from healthy volunteers.

The concentration of the calibration samples in plasma were 5, 25, 50, 100, 300, 500, 700, 1000 and $1500 \mathrm{ng} / \mathrm{mL}$ for ART/ DHA and 5, 25, 100, 300, 900, 1500, 2500, 4000 and 5000 $\mathrm{ng} / \mathrm{mL}$ for LUM/ DBL. Quality control (QC) samples in plasma were prepared in a similar way, at high, middle and low concentrations: 25,350 and $560 \mathrm{ng} / \mathrm{mL}$ for ART/ DHA and 25, 1600 and $3200 \mathrm{ng} / \mathrm{mL}$ for LUM/ DBL.

\section{Sample preparation}

A $50 \mu \mathrm{L}$ aliquot of the IS solution $(10 \mu \mathrm{g} / \mathrm{mL}$ of MQ in methanol) was added to $150 \mu \mathrm{L}$ of the plasma sample in a clean $1.5 \mathrm{~mL}$ polypropylene tube. A $300 \mu \mathrm{L}$ aliquot of glacial acetic acid $0.5 \%(\mathrm{v} / \mathrm{v})$ in methanol was added, the sample was vortex-mixed for 40 seconds followed by centrifugation $\left(3500 \mathrm{x} \mathrm{g} ; 10 \mathrm{~min} . ; 4^{\circ} \mathrm{C}\right)$. The supernatant was transferred into an autosampler vial and submitted for analysis with a volume of $20 \mu \mathrm{L}$ being injected into the chromatographic system.

\section{METHOD VALIDATION}

The validation process was carried out according to Guidance for Industry-Bioanalytical Method Validation, recommended by the US Food and Drug Administration (Van A. et al., 2013). The validation parameters evaluated were selectivity, linearity and sensitivity, extraction recovery, accuracy and precision, stability, matrix effect and carry over.

\section{Selectivity}

Selectivity of the method was assessed and assured by analysis of six independent blank plasma from different sources, each blank sample was tested for interference using the proposed extraction procedure and chromatographic/mass spectrometric conditions and compared to those containing ART, DHA, LUM and DBL at lower limits of quantitation (LLOQ) or MQ at $1000 \mathrm{ng} / \mathrm{mL}$. In addition, plasma samples spiked with commonly used antimalarials and analgesics (sulfadoxine, artesunate and paracetamol each at $1000 \mathrm{ng} / \mathrm{mL}$ ) were also evaluated to ensure there were no interferences in the method. 


\section{Linearity and $L L O Q$}

Linearity of the calibration curves were assessed assaying standard plasma samples at nine concentrations in the range of $5-1500 \mathrm{ng} / \mathrm{mL}$ for ART/DHA and $5-5000 \mathrm{ng} / \mathrm{mL}$ for LUM/DBL on three consecutive days. The curves were constructed by plotting the peak-area ratio of each antimalarial drug to that of the IS verses the nominal concentration of the drug. The curves were evaluated and fitted by weighted $(1 / x)$ linear regression. The LLOQ was defined as the lowest concentration on the calibration curve, at which an acceptable accuracy (relative error, RE) within $\pm 20 \%$ and a precision (relative standard deviation, RSD) below $15 \%$ can be obtained by means of analyses of at least five replicates from a homogenous sample.

\section{Accuracy and precision}

The intra-day accuracy and precision of the method were evaluated by analyzing six replicates of QC samples at three concentration levels $(25,350,560 \mathrm{ng} / \mathrm{mL}$ for ART/DHA and $25,1600,3200 \mathrm{ng} / \mathrm{mL}$ for LUM/DBL) on the same day. Inter-day accuracy and precision was determined by analyzing freshly prepared QC samples (six replicates) at three concentration levels on three consecutive days. Each validation run consisted of one set of calibration standards and six replicates of QC samples at three concentration levels.

\section{Extraction recovery and matrix effect}

The extraction recovery of the method was determined by analyzing six replicates of plasma samples at three QC concentration levels of 25, 350, $560 \mathrm{ng} / \mathrm{mL}$ (ART/DHA) and $25,1600,3200 \mathrm{ng} / \mathrm{mL}$ (LUM/DBL) corresponding to low, medium and high QCs. The recovery was calculated by comparing the peak areas obtained from extracted spiked samples (A) with those of samples spiked post-extraction (B) at corresponding concentrations. Matrix effect was evaluated to verify whether ion suppression or enhancement due to the co-elution matrix components existed in the analysis. The peak areas of the analytes and the IS from the post-extraction (protein precipitation) matrix spike samples were compared to those of the standard solutions in the mobile phase at the same concentrations. This experiment was carried out with blank plasma samples from six different sources at low and high QC concentrations of ART, DHA, LUM and DBL. The extraction recovery and matrix effect of IS at a single concentration of $1000 \mathrm{ng} / \mathrm{mL}$ were also evaluated using the same procedure.

\section{Stability}

The stability of the analytes in human plasma was assessed by analyzing six replicates of low and high QC samples under different temperature and time conditions. The freezethaw stability was performed by subjecting QC plasma samples to three freeze $\left(-20{ }^{\circ} \mathrm{C}\right)-$ thaw cycles at ambient temperature $\left(24{ }^{\circ} \mathrm{C}\right)$. QC samples were stored frozen at $-20{ }^{\circ} \mathrm{C}$ for 60 days and analyzed after allowing to thaw unassisted at ambient temperature to determine the long-term stability. Short-term stability was assessed by keeping QC samples at ambient temperatures for $8 \mathrm{~h}$ before processing and analyses. The post-preparation stability was studied by analyzing the processed QC samples kept in the autosampler at $4{ }^{\circ} \mathrm{C}$ for 15 h. Sub-stock solution stability was evaluated for the analytes, by comparing the response 
generated from the same solution at preparation and after being stored at $-20 \circ \mathrm{C}$ for a period of 28 days. The IS was freshly prepared on every day of analysis. The analytes were considered stable when the concentrations found were within $\pm 15 \%$ of the initial concentration.

$$
S T \%=\frac{c_{t}}{c_{0}} \times 100 \%
$$

Where $\mathrm{c}_{0}$ is the initial concentration, determined without introducing any extra pauses in the analysis process; $\mathrm{c}_{t}$ is the concentration obtained after the storage period with time $t$.

\section{Pharmacokinetics study}

The validated method was used to determine the plasma concentration of ART, LUM and their principle metabolites in a pharmacokinetic study with fixed-dose combination tablets in three healthy volunteers. The volunteers received single oral dose of 80mg ART and $480 \mathrm{mg}$ LUM, corresponding to four tablets of the fixed-dose combination with milk. Blood samples $(2 \mathrm{~mL})$ were collected into heparinized tubes at $0,0.5,1,1.5,2,3,6,8$, 10, and 12h. Dosing was administered just after the pre dose sampling. Plasma samples were obtained by centrifugation at $2000 \mathrm{rpm}$ for $10 \mathrm{~min}$ and frozen at $-80{ }^{\circ} \mathrm{C}$ until the analyses.

\section{RESULTS AND DISCUSSION}

\section{Optimization of mass spectrometry}

The LC-MS/MS operation parameters were carefully optimized for the simultaneous determination of ART, LUM and their principle metabolites. The mass spectrometer was tuned in the positive ionization mode with ESI for optimum response of all the analytes as previous attempts to use atmospheric pressure chemical ionization (APCI) resulted to low intensities of ART precursor ions and poor detection of LUM (Sandrenan N. et al., 1997; Souppart C. et al., 2002). Parameters such as desolvation temperature, ESI source temperature, capillary and cone voltage, flow rate of desolvation gas and cone gas were optimized to obtain the highest intensity of the molecular ions of the analytes and IS. Whereas Xing et al., 2006 and Sabarinath et al., 2003 had performed successful quantitation of artemisinin derivatives by LC-MS/MS using ESI by monitoring the ammonium adduct $\left[\mathrm{M}+\mathrm{NH}_{4}\right]^{+}$as the precursor ion, the $0.5 \%$ formic acid in $20 \mathrm{mM}$ ammonium formate used in this method produced desirable precursor ions intensities $\left[\mathrm{M}+\mathrm{NH}_{4}\right]^{+}$of $\mathrm{ART} \mathrm{m} / \mathrm{z} 316$ and $\mathrm{DBL} \mathrm{m} / \mathrm{z} 302$ while at the same time facilitating the protonation $[\mathrm{M}+\mathrm{H}]^{+}$of LUM precursor ion $\mathrm{m} / \mathrm{z} 530$ and DBL m/z 472 .

ART and DHA presented the same intense product ion at $\mathrm{m} / \mathrm{z} 163$ at a collision energy of $10 \mathrm{eV}$. For LUM, the major product ion was $\mathrm{m} / \mathrm{z} 512$, at a collision energy of $30 \mathrm{eV}$. The product ion mass spectra of ART, LUM and their principle metabolites are presented in Figure 2. 

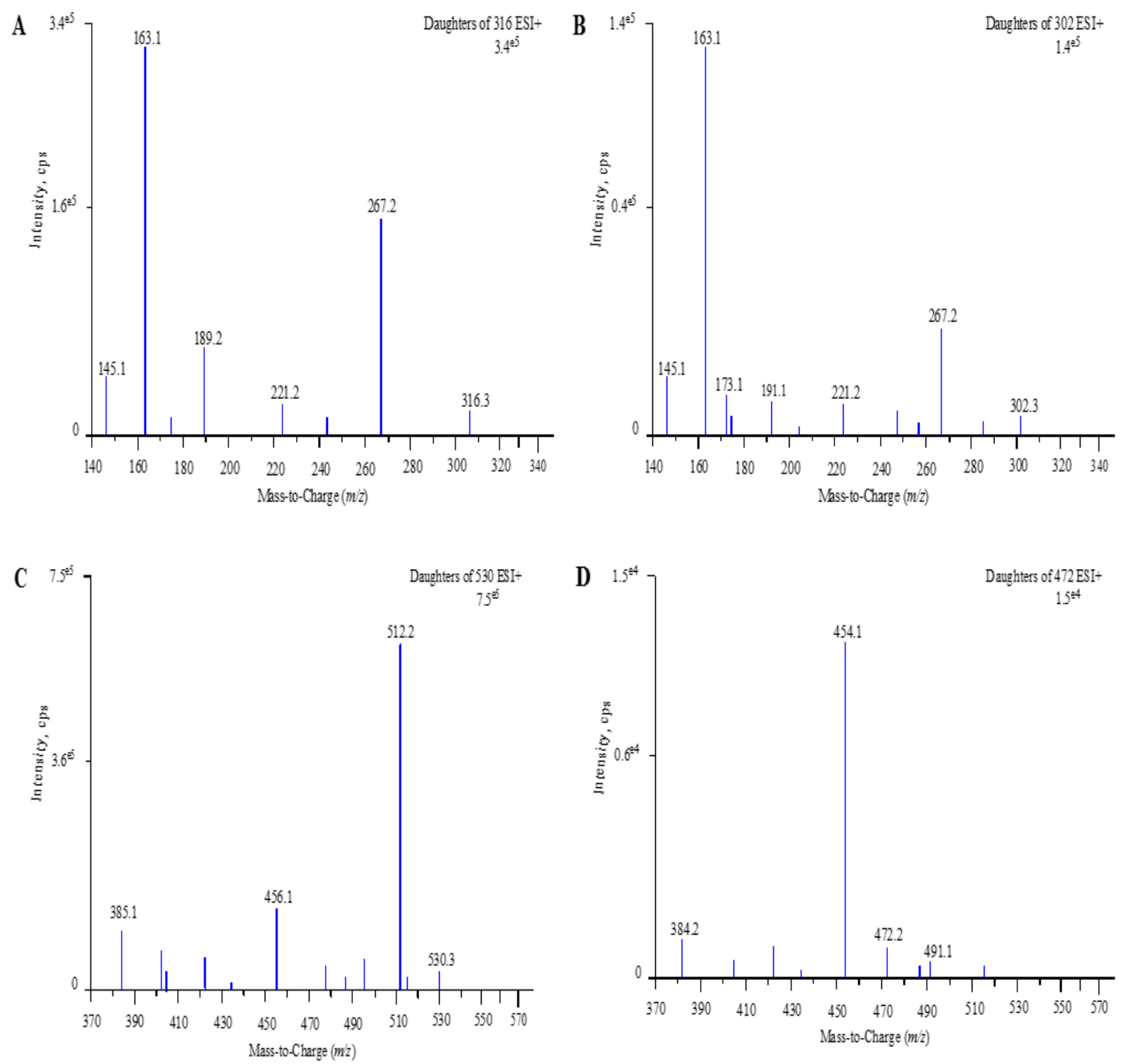

Figure 2. Product ion mass spectra for artemether (A), dihydroartemisinin (B), lumefantrine (C) and desbutyllumefantrine (D). The most intense ions were monitored and used for quantitation.

\section{Optimization of chromatography}

During the method development, several chromatographic conditions were optimized to ensure good peak symmetry, sharp peaks and well resolved peaks. The use of $20 \mathrm{mM}$ ammonium formate buffer in the mobile phase was necessitated for detection of the ammonium adducts $\left[\mathrm{M}+\mathrm{NH}_{4}\right]^{+}$of ART and DHA. The mobile phase acidification with formic acid was to ensure adequate LUM and DBL peak shape and to promote the ionization of the analytes in the positive mode by protonation $[\mathrm{M}+\mathrm{H}]^{+}$. Various ratios $(20: 80,70: 30,60: 40 \mathrm{v} / \mathrm{v}$ of $20 \mathrm{mM}$ ammonium formate buffer: methanol) were evaluated, high recovery percentages due to an ionization enhancement of the analytes was encountered for LUM and DBL due to matrix effect. Thus, a linear gradient elution program was employed, using $60 \%$ acetonitrile (solvent B) at $0 \mathrm{~min}$ and $75 \% \mathrm{~B}$ at 2 minutes, so that no matrix effect was verified in this optimized 
condition. The re-equilibration phase lasted 2 minutes, with $60 \%$ acetonitrile with a total run time of 5 minutes. The retention times were about 1.3 (DHA), 1.7 (ART and MQ), 3.0 (DBL) and 3.9 min for LUM. The chromatograms obtained with this developed method are shown in Figures 3.

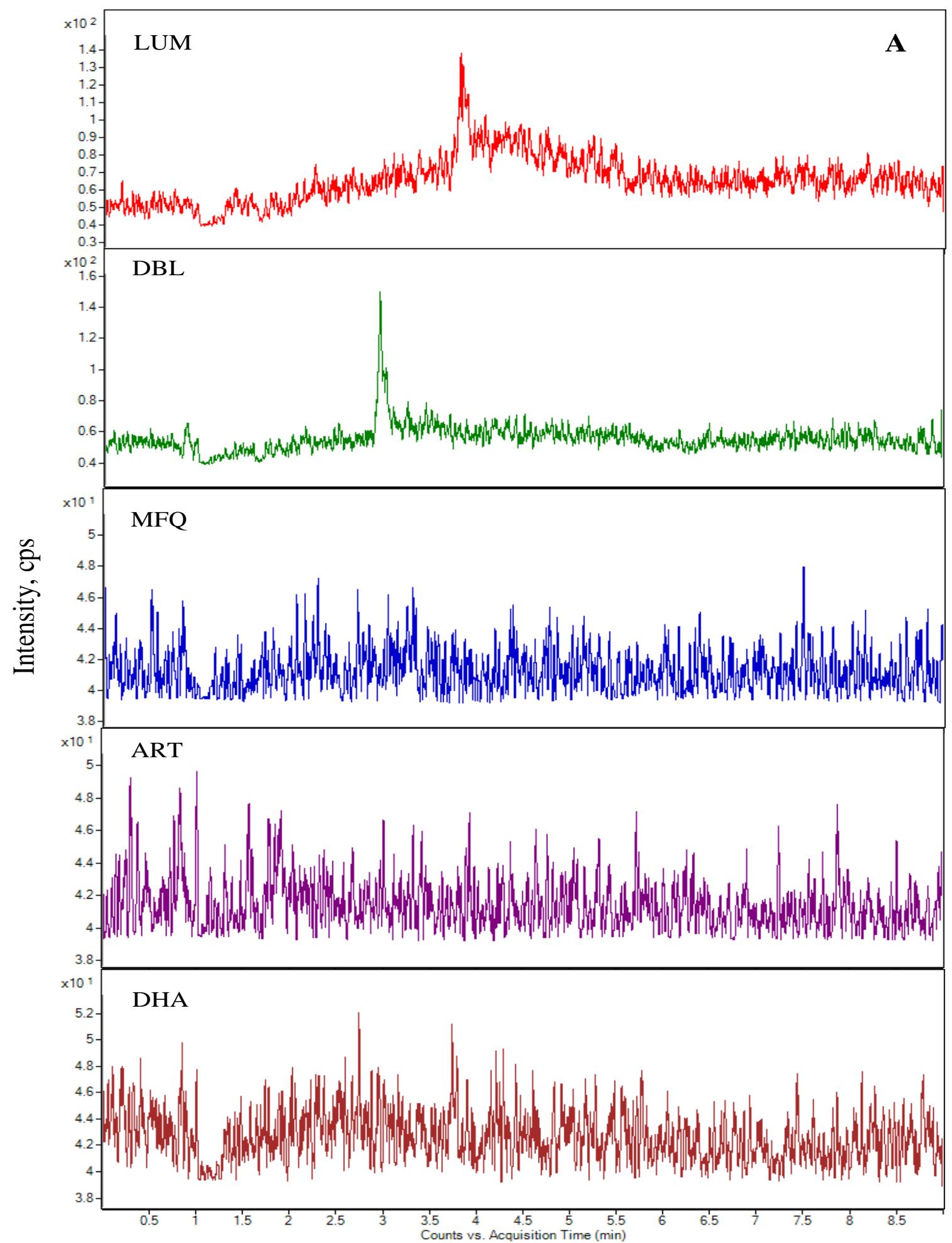

Figure 3A. Representative chromatograms of processed blank plasma at for DHA, ART, MFQ, DBL and LUM 


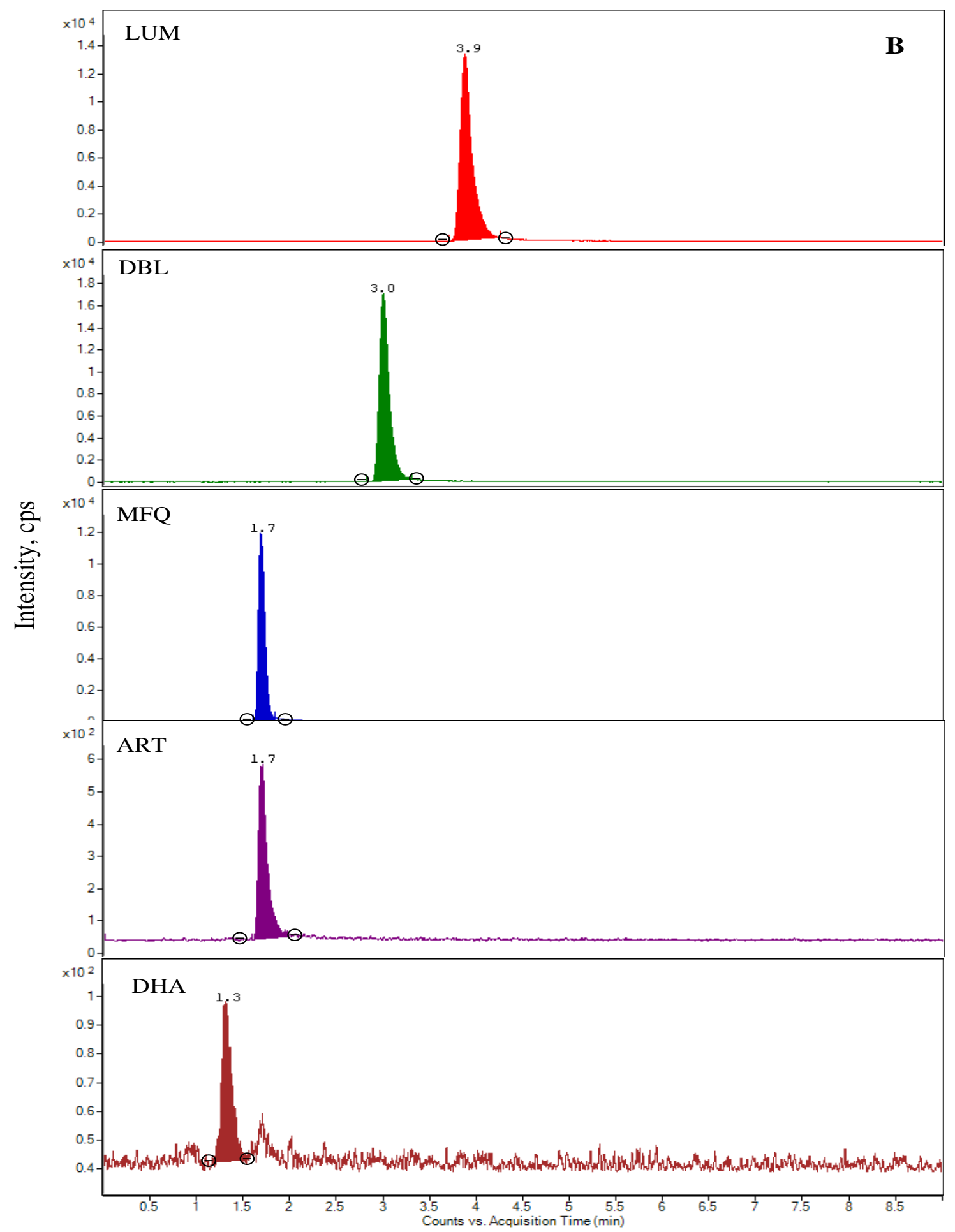

Figure 3B. Representative chromatograms of processed spiked plasma at LOQ of 25ng/mL for DHA (RT $1.3 \mathrm{~min}$ ), ART (RT 1.7 min), DBL (RT 3.0 min) and LUM (RT $3.9 \mathrm{~min})$.

\section{Selection of extraction method}

Several extraction methods were tried, since all the analytes and the IS significantly differs in drug-plasma binding and physicochemical properties, it was difficult to optimize extraction 
procedure for all the analytes and IS from plasma. Several approaches were tried based on the previously reported methods such as protein precipitation (PPT) (Hodel et al., 2009), solid phase extraction (SPE) and liquid-liquid extraction (LLE) (Khuda et al., 2016). Finally PPT procedure with methanol was chosen. This was found to be economical and considerably less laborious compared to the LLE used in previous publications. The validated proteinprecipitation procedure is simple and resulted in high recovery percentage for all the drugs, the procedure does not require sophisticated apparatus and thus applicable even within resourcelimited laboratories.

\section{Method validation}

All the lots of blank plasma used for selectivity studies met the acceptance criteria. Figure 3 show the typical chromatograms of extracted blank plasma (A) a spiked plasma sample with the analytes at LLOQ (B). These results support the high selectivity and specificity of this method as there were no interfering peaks from endogenous compounds observed at the retention times of the analytes and the IS, nor any interfering peaks from the commonly used antimalarials and analgesics (sulfadoxine, artesunate and paracetamol) at the ions selected for analyte quantitation.

The calibration curves for analytes spiked in plasma were found to be linear over the concentration ranges of 5-1500 ng/mL (ART/DHA) and 5-5000 ng/mL (LUM/DBL) with a regression coefficient greater than 0.9992 . A weighted $(1 / \mathrm{x})$ linear regression model was used by determining the best fit of the peak-area ratios (peak area of analyte/ peak area of IS) vs analyte concentration and conformed to $\mathrm{y}=\mathrm{mx}+\mathrm{c}$ (where $\mathrm{y}$ - peak area ratio; $\mathrm{x}$ - concentration; c- slope of the curve). The choice of this regression model was based on all available data from the validation phase, in light of this the method proved to be reliable in terms of accuracy and reproducibility over the entire calibration range. Typical regression parameters for the calibration curves are summarized (Table S1). The LLOQs were determined by the needs of the method and defined as the lowest standards on the calibration curve with identifiable, discrete, and reproducible with a precision $\leq 20 \%$ and accuracy within $85 \%-115 \%$. The limits of detection (LODs) were determined as the lowest concentration of the analyte at which the signal to noise (S/N) ratio exceeded 3:1 (Van A. et al., 2013), these were $3 \mathrm{ng} / \mathrm{mL}$ (ART/DHA) and $2 \mathrm{ng} / \mathrm{mL}$ for (LUM/DBL).

\begin{tabular}{|c|c|c|c|c|c|}
\hline $\begin{array}{c}\text { Intra-assay } \\
(n=6)\end{array}$ & Analyte & $\begin{array}{c}\text { Nominal } \\
\text { concentration } \\
(\mathrm{ng} / \mathrm{mL})\end{array}$ & $\begin{array}{l}\text { Mean estimated } \\
\text { concentration } \\
(\mathrm{ng} / \mathrm{mL}) \pm \mathrm{SD}\end{array}$ & $\begin{array}{l}\text { Precision } \\
\text { (CV \%) }\end{array}$ & $\begin{array}{c}\text { Accuracy } \\
(\%)\end{array}$ \\
\hline & ART & $\begin{array}{l}25 \\
350 \\
560\end{array}$ & $\begin{array}{l}23.7 \pm 1.6 \\
322.6 \pm 6.7 \\
531.3 \pm 4.0\end{array}$ & $\begin{array}{l}2.2 \\
5.7\end{array}$ & $\begin{array}{l}94.8 \\
92.2 \\
94.9\end{array}$ \\
\hline & DHA & $\begin{array}{l}25 \\
350 \\
560\end{array}$ & $\begin{array}{l}24.2 \pm 4.4 \\
526.7 \pm 5.9 \\
527.4 \pm 4.3\end{array}$ & $\begin{array}{l}6.1 \\
1.8 \\
3.3\end{array}$ & $\begin{array}{l}96.7 \\
93.3 \\
94.2\end{array}$ \\
\hline & LUM & $\begin{array}{r}25 \\
1600 \\
3200\end{array}$ & $\begin{array}{r}23.5=1.8 \\
1566.0=1.5 \\
2948.2=4.3\end{array}$ & $\begin{array}{l}2.5 \\
1.6 \\
1.5\end{array}$ & $\begin{array}{l}93.8 \\
97.9 \\
92.1\end{array}$ \\
\hline & DBI & $\begin{array}{r}25 \\
1600 \\
3200\end{array}$ & $\begin{array}{r}26.2 \pm 5.4 \\
1743.4 \pm 1.5 \\
3025.6 \pm 4.3\end{array}$ & $\begin{array}{l}6.8 \\
3.8 \\
3.4\end{array}$ & $\begin{array}{l}104.9 \\
109.0 \\
94.5\end{array}$ \\
\hline \multirow[t]{4}{*}{$\begin{array}{c}\text { Inter-assay } \\
(n=18)\end{array}$} & ART & $\begin{array}{l}25 \\
350 \\
560\end{array}$ & $\begin{array}{r}24.5=3.3 \\
328.3 \pm 3.0 \\
531.4=2.8\end{array}$ & $\begin{array}{l}3.4 \\
3.2 \\
2.9\end{array}$ & $\begin{array}{l}97.8 \\
93.8 \\
99.3\end{array}$ \\
\hline & DHA & $\begin{array}{l}25 \\
350 \\
560\end{array}$ & 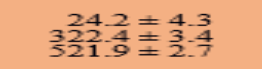 & $\begin{array}{l}\frac{4}{3} \cdot \frac{4}{2} \\
\frac{1}{3}\end{array}$ & $\begin{array}{l}96.8 \\
91: 1 \\
93.2\end{array}$ \\
\hline & LUM & $\begin{array}{c}25 \\
1600 \\
3200\end{array}$ & $\begin{array}{r}25.1 \\
166.1 \\
3628.8 \\
3027 \pm 2.4\end{array}$ & $\begin{array}{l}6.1 \\
4.7\end{array}$ & $\begin{array}{l}100.7 \\
194.3\end{array}$ \\
\hline & DBL & $\begin{array}{l}1600 \\
3200\end{array}$ & $\begin{array}{l}1726.7 \pm 5.5 \\
1723.2=2.8 \\
3024.0 \pm 1.6\end{array}$ & $\frac{5}{2} \cdot \frac{1}{6}$ & $\begin{array}{l}196.9 \\
187.7 \\
94.5\end{array}$ \\
\hline
\end{tabular}

Table 2. Intra-assay and inter-assay accuracy and precision of artemether (ART), dihydroartemisinin (DHA), lumefantrine (LUM) and desbutyl-lumefantrine (DBL) in plasma at LOQ, MOQ and HOQ. 


\begin{tabular}{|c|c|c|c|c|c|c|c|c|c|}
\hline \multirow[t]{2}{*}{ Stability parameters } & \multirow[t]{2}{*}{ Spiked conc. ( $\mathrm{ng} / \mathrm{mL})$} & \multicolumn{2}{|c|}{ ART } & \multicolumn{2}{|c|}{ DHA } & \multicolumn{2}{|c|}{ LUM } & \multicolumn{2}{|c|}{ DBL } \\
\hline & & 25 & 560 & 25 & 560 & 25 & 3200 & 25 & 3200 \\
\hline \multirow[t]{3}{*}{$\begin{array}{l}\text { Bench-top stability in matrix } \\
\text { (ambient temberature. } 8 \mathrm{~h} \text { ) }\end{array}$} & $\begin{array}{l}\text { Mean stability of } \\
\text { samvles }\end{array}$ & 23.4 & 518.0 & 26.3 & 536.5 & 24.6 & 3203.2 & 24.6 & 3027.2 \\
\hline & CV $\%$ & 3.0 & 2.1 & 2.2 & 4.6 & 5.6 & 8.4 & 6.9 & 3.6 \\
\hline & ST $\%$ & 93.6 & 92.5 & 105.3 & 95.8 & 98.5 & 100.1 & 98.3 & 94.6 \\
\hline \multirow[t]{3}{*}{$\begin{array}{l}\text { Freeze-thaw stability } \\
\left(3 \text { freeze-thaw cycles at }-20^{\circ} \mathrm{C} \text { ) }\right.\end{array}$} & $\begin{array}{l}\text { Mean stability of } \\
\text { samples }\end{array}$ & 24.0 & 553.8 & 23.0 & 527.0 & 23.1 & 3270.4 & 24.7 & 3052.8 \\
\hline & CV $\%$ & 4.1 & 8.5 & 3.0 & 4.7 & 3.4 & 6.1 & 3.9 & 6.9 \\
\hline & $\mathrm{ST} \%$ & 96.0 & 98.9 & 91.9 & 94.1 & 92.3 & 102.2 & 98.8 & 95.4 \\
\hline \multirow[t]{3}{*}{$\begin{array}{l}\text { Post-preparative stability } \\
\left(15 \mathrm{~h} \text { at } 18^{\circ} \mathrm{C}\right)\end{array}$} & $\begin{array}{l}\text { Mean stability of } \\
\text { samples }\end{array}$ & 25.1 & 521.4 & 24.1 & 524.2 & 25.4 & 3078.4 & 24.2 & 3058.7 \\
\hline & CV $\%$ & 3.4 & 2.4 & 3.0 & 2.2 & 3.6 & 1.8 & 3.8 & 3.0 \\
\hline & $\mathrm{ST} \%$ & 100.5 & 93.1 & 96.5 & 93.6 & 101.7 & 96.2 & 96.9 & 95.6 \\
\hline \multirow[t]{3}{*}{$\begin{array}{l}\text { Long-term stability } \\
\left(60 \text { days at }-20^{\circ} \mathrm{C}\right)\end{array}$} & $\begin{array}{l}\text { Mean stability of } \\
\text { samples }\end{array}$ & 21.4 & 518.0 & 24.0 & 554.4 & 24.2 & 3145.6 & 24.9 & 3152.0 \\
\hline & CV \% & 2.2 & 2.7 & 6.1 & 3.3 & 2.5 & 3.8 & 3.8 & 3.0 \\
\hline & $\mathrm{ST} \%$ & 85.5 & 92.5 & 96.0 & 99.0 & 96.9 & 98.3 & 99.6 & 98.5 \\
\hline \multirow[t]{4}{*}{$\begin{array}{l}\text { Sub-stock solution stability } \\
\left(28 \text { days at }-20^{\circ} \mathrm{C}\right)\end{array}$} & $\begin{array}{l}\text { Nominal Conc. } \\
(\mu \mathrm{g} / \mathrm{mL})\end{array}$ & & 10 & & 10 & & 50 & & 50 \\
\hline & $\begin{array}{l}\text { Mean stability of } \\
\text { samples }\end{array}$ & & 9.0 & & 9.4 & & 47.9 & & 46.8 \\
\hline & CV $\%$ & & 3.2 & & 2.8 & & 3.6 & & 2.9 \\
\hline & $\mathrm{ST} \%$ & & 90.2 & & 94.0 & & 95.8 & & 93.5 \\
\hline
\end{tabular}

Table 3. Stability (ST \%) of artemether (ART), dihydroartemisinin (DHA), lumefantrine (LUM) and desbutyllumefantrine $(\mathrm{DBL})$ in plasma with the coefficient of variation $(\mathrm{CV} \%)(\mathrm{n}=6)$.

To evaluate the inter-assay precision and accuracy, six replicates of quality control (LQC, MQC and HQC) plasma samples were analyzed together with one independent calibration standard curve, this was done in three consecutive days; while intra-assay precision and accuracy were evaluated by analysis of quality control plasma samples in replicate of six in the same day. Inter-assay and intra-assay precision were expressed as coefficient of variation (CV $\%)$. The accuracy was expressed as the percent ratio between the experimental concentrations and the nominal concentration for each sample. Assay accuracy of the method was above 92.1\% and precision values did not exceed $6.8 \%$ for both intra and inter-assay experiments (Table 2). The accuracy and precision data evidently show that the method meet the acceptance criteria of accuracy and precision hence reliable in quantifying the drugs.

The protein precipitation method of extraction with acidified methanol yielded high recoveries with better reproducibility of the analytes than in the previously reported publications (Navaratnam V. et al., 1995; Sandrenan N. et al., 1997; Souppart C. et al., 2002; Shi B. et al., 2006). The addition of acetic to methanol for precipitation improved the recoveries of LUM and DBL considerably (Table S2). Matrix effect experiments carried out by direct pre-column infusion of processed blank plasma lots revealed no significant ion enhancement or suppression to the transition ions chosen for analysis in this method. Figure S1 is an overlaid chromatogram of post-column infusion of processed blank plasma and plasma sample at LLOQ of the analytes. In this present method therefore, the matrix effects on all the analytes were not significant. 
The results of all the stability studies experiments were well within the acceptable limits of accuracy $( \pm 15 \%)$ and precision $(\mathrm{CV} \leq 15 \%)$. The long-term stability duration (60 days) under which the study was conducted was necessitated by the need to minimize the period for storage of the real study samples. Whereas César et al., 2008 and Hodel et al., 2009 have studied the stabilities of these drugs over a longer period, this method focused on their stability under storage at -20 oC which is the common setup with resource-limited facilities. Nonetheless, all the analytes indicated acceptable stability at the storage temperature, $85.5-99.6 \%$ of the original concentration was found after the storage period of 60 days. Artemether however recorded the lowest value due to its labile endoperoxide bridge (Table 3). Bench-top and post-processing stability results indicate that all the drugs were stable through the investigated period of experiments.

Therefore the sample processing procedure reported here can be used in analyses of large number of samples without the risk of sample degradation due to room temperature exposure, similarly re-analysis of the processed samples can be initiated in case of equipment failure during an analytical run without compromising sample integrity. All the analytes met the stability criteria after the three freeze and thaw cycles, the sub-stock solutions were also found stable (90.2-95.8\%), and fresh stock solutions were prepared after the 28 days.

\section{Application of the method to a clinical pharmacokinetics study}

The validated method was successfully applied to a pharmacokinetic study of ART, LUM and their principle metabolites in healthy volunteers following a single oral dose with Coartem ${ }^{\circledR}$ (80 mg ART and $480 \mathrm{mg}$ LUM) over a course of $12 \mathrm{~h}$. The sensitivity and specificity of the method showed to be adequate for accurately characterizing the pharmacokinetics of ART, LUM and their metabolites. The mean plasma concentrations of ART /DHA and LUM/LUM after an oral administration of a single dose of $80 \mathrm{mg}$ of ART and 480mg of LUM were highest at around $1 \mathrm{~h}$ and $6 \mathrm{~h}$ respectively (Figure 4). The chromatograms of patient samples at the two sampling times are shown in (Figure S2). These results are consistent with those previously reported (Ezzet F. et al., 2000 ; Shi B. et al., 2006), which demonstrate a rapid absorption and elimination of ART, while LUM presented a long elimination half-life and could be detected in the patients' plasma for up to $48 \mathrm{~h}$ post dose.

This method requires very small plasma volumes and will allow the assay of drug and metabolite concentrations following administration ART/LUM in people who can only provide small volumes of blood such as infants and children.

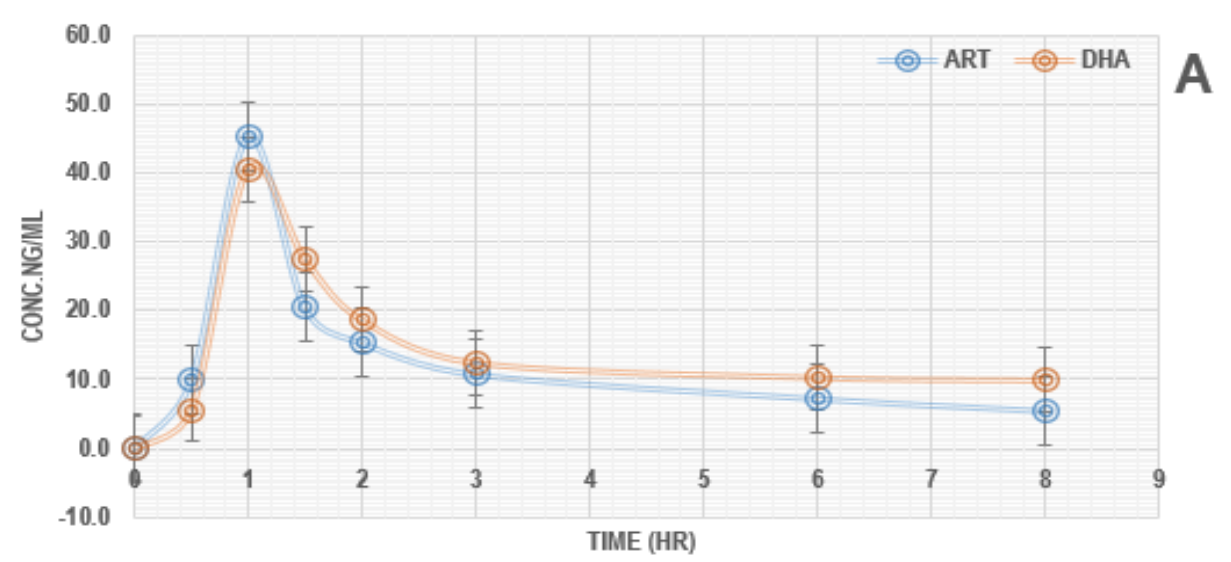




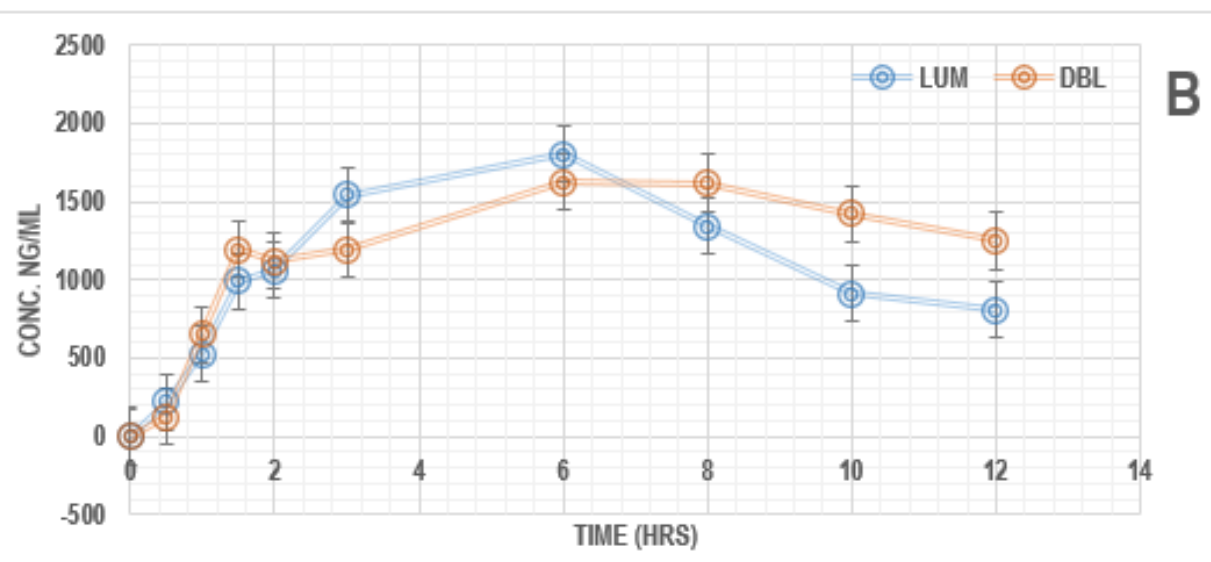

Figure 4. Mean plasma concentrations of ART, DHA (A) and LUM, DBL (B) after an oral administration of a single dose of $80 \mathrm{mg}$ artemether and $480 \mathrm{mg}$ lumefantrine to healthy volunteers, the bars represents a \pm 2 standard error value on the mean concentrations.

\section{CONCLUSION}

The validated HPLC-ESI-MS/MS method allowed the simultaneous quantitation of ART, LUM and their principle metabolites from only $150 \mu \mathrm{L}$ human plasma, provided simple and rapid analyses, as well as sensitive and reliable results. Therefore, this method proved to be suitable for routine high-throughput analyses and may be successfully applied to pharmacokinetic and bioequivalence of multiple doses evaluated in the present in human subjects.

\section{Acknowledgments}

This work is published with the permission of the Director of the Kenya Medical Research Institute (KEMRI). We wish to thank the Consortium for National Health Research (CNHR) who provided the study grant that enabled the conduct and publication of this study.

\section{Conflict of Interest}

The authors have no other relevant affiliations or financial involvement with any organization or entity with a financial interest in or financial conflict with the subject matter or materials discussed in the manuscript, apart from those disclosed. No writing assistance was utilized in the production of this manuscript.

\section{References}

Annerberg, A., et al. (2005), "High Throughput Assay for the Determination of Lumefantrine in Plasma." Journal of Chromatography B, vol. 822, no. 1-2, pp. 330-33. Crossref, doi:10.1016/j.jchromb.2005.06.022.

Ashley, Elizabeth A., et al. (2007), "Pharmacokinetic Study of Artemether-Lumefantrine given Once Daily for the Treatment of Uncomplicated Multidrug-Resistant Falciparum Malaria: Once-Daily ArtemetherLumefantrine to Treat Falciparum Malaria.” Tropical Medicine \& International Health, vol. 12, no. 2, pp. 201-08. Crossref, doi:10.1111/j.1365-3156.2006.01785.x. 
César, Isabela da Costa, et al. (2008), "Simultaneous Determination of Artemether and Lumefantrine in Fixed Dose Combination Tablets by HPLC with UV Detection.” Journal of Pharmaceutical and Biomedical Analysis, vol. 48, no. 3, pp. 951-54. Crossref, doi:10.1016/j.jpba.2008.05.022.

Ezzet, F., et al. (2000), "Pharmacokinetics and Pharmacodynamics of Lumefantrine (Benflumetol) in Acute Falciparum Malaria.” Antimicrobial Agents and Chemotherapy, vol. 44, no. 3, pp. 697-704. Crossref, doi:10.1128/AAC.44.3.697-704.2000.

Global Report on Antimalarial Drug Efficacy and Drug Resistance: 2000-2010. World Health Organization, 2010.Open World Cat, http://whqlibdoc.who.int/publications/2010/9789241500470_eng.pdf.

Hodel, E. M., et al. (2009), “A Single LC-Tandem Mass Spectrometry Method for the Simultaneous Determination of 14 Antimalarial Drugs and Their Metabolites in Human Plasma.” Journal of Chromatography B, vol. 877, no. 10, pp. 867-86. Crossref, doi:10.1016/j.jchromb.2009.02.006.

Karbwang, J., et al. (1997), "Determination of Artemether and Its Major Metabolite, Dihydroartemisinin, in Plasma Using High-Performance Liquid Chromatography with Electrochemical Detection.” Journal of Chromatography B: Biomedical Sciences and Applications, vol. 690, no. 1-2, pp. 259-65. Crossref, doi:10.1016/S0378-4347(96)00422-7.

Karbwang, J., et al. (1997), "Pharmacokinetics and Bioavailability of Oral and Intramuscular Artemether." European Journal of Clinical Pharmacology, vol. 52, no. 4, pp. 307-10. Crossref, doi:10.1007/s002280050295.

Khuda, Fazli, et al. (2016), “A High-Resolution LC-MS/MS Method for the Quantitative Determination of Artemether and Its Metabolite Dihydroartemisinin in Human Plasma and Its Application to Pharmacokinetic Studies.” Chromatographia, vol. 79, no. 9-10, pp. 609-18. Crossref, doi:10.1007/s10337-0163064-6.

Lindegårdh, N., et al. (2005), "Development and Validation of a Bioanalytical Method Using Automated SolidPhase Extraction and LC-UV for the Simultaneous Determination of Lumefantrine and Its Desbutyl Metabolite in Plasma." Journal of Pharmaceutical and Biomedical Analysis, vol. 37, no. 5, pp. 108188. Crossref, doi:10.1016/j.jpba.2004.07.041.

Mansor, Sharif M., et al. (1996), "Determination of a New Antimalarial Drug, Benflumetol, in Blood Plasma by High-Performance Liquid Chromatography.” Journal of Chromatography B: Biomedical Sciences and Applications, vol. 682, no. 2, pp. 321-25. Crossref, doi:10.1016/0378-4347(96)00086-2.

Martensson, A., et al. (2005), "Efficacy of Artesunate Plus Amodiaquine versus That of Artemether-Lumefantrine for the Treatment of Uncomplicated Childhood Plasmodium Falciparum Malaria in Zanzibar, Tanzania." Clinical Infectious Diseases, vol. 41, no. 8, pp. 1079-86. Crossref, doi:10.1086/444460.

McGready, Rose, et al. (2006), "The Pharmacokinetics of Artemether and Lumefantrine in Pregnant Women with Uncomplicated Falciparum Malaria.” European Journal of Clinical Pharmacology, vol. 62, no. 12, pp. 1021-31. Crossref, doi:10.1007/s00228-006-0199-7.

Mugoyela, Veronica, and Omary Minzi. (2011), "Implementation of Artemether-Lumefantrine Treatment Policy for Malaria at Health Facilities in Tanzania.” Risk Management and Healthcare Policy, p. 89. Crossref, doi:10.2147/RMHP.S23054.

Navaratnam, V., et al. (1995), "Determination of Artemether and Dihydroartemisinin in Blood Plasma by HighPerformance Liquid Chromatography for Application in Clinical Pharmacological Studies.” Journal of Chromatography B: Biomedical Sciences and Applications, vol. 669, no. 2, pp. 289-94. Crossref, doi:10.1016/0378-4347(94)00109-I.

Omari, Aika A., et al. (2004), “Artemether-Lumefantrine for Uncomplicated Malaria: A Systematic Review." Tropical Medicine and International Health, vol. 9, no. 2, pp. 192-99. Crossref, doi:10.1046/j.13653156.2003.01186.x.

Sabarinath, S., et al. (2003), "A Sensitive and Selective Liquid Chromatographic/Electrospray Ionization Tandem Mass Spectrometric Assay for the Simultaneous Quantification of ?-,?-Arteether and Its Metabolite Dihydroartemisinin in Plasma, Useful for Pharmacokinetic Studies.” Journal of Mass Spectrometry, vol. 38, no. 7, pp. 732-42. Crossref, doi:10.1002/jms.487.

Sandrenan, N., et al. (1997), "Determination of Artemether and Its Metabolite, Dihydroartemisinin, in Plasma by High-Performance Liquid Chromatography and Electrochemical Detection in the Reductive Mode." Journal of Chromatography B: Biomedical Sciences and Applications, vol. 691, no. 1, pp. 145-53. Crossref, doi:10.1016/S0378-4347(96)00431-8.

Shi, Bin, et al. (2006), "Quantitative Analysis of Artemether and Its Metabolite Dihydroartemisinin in Human Plasma by LC with Tandem Mass Spectrometry.” Chromatographia, vol. 64, no. 9-10, pp. 523-30. Crossref, doi:10.1365/s10337-006-0064-y. 
Souppart, C., et al. (2002), "Development and Validation of a High-Performance Liquid Chromatography-Mass Spectrometry Assay for the Determination of Artemether and Its Metabolite Dihydroartemisinin in Human Plasma.” Journal of Chromatography B, vol. 774, no. 2, pp. 195-203. Crossref, doi:10.1016/S1570-0232(02)00207-6.

Van, A., Peter, et al. (2013), “The European Bioanalysis Forum Community's Evaluation, Interpretation and Implementation of the European Medicines Agency Guideline on Bioanalytical Method Validation." Bioanalysis, vol. 5, no. 6, pp. 645-59. Crossref, doi:10.4155/bio.13.19.

Wahajuddin, et al. (2009), "Determination of Lumefantrine in Rat Plasma by Liquid-Liquid Extraction Using LC-MS/MS with Electrospray Ionization: Assay Development, Validation and Application to a Pharmacokinetic Study.” Journal of Chromatography B, vol. 877, no. 11-12, pp. 1133-39. Crossref, doi:10.1016/j.jchromb.2009.02.058.

White, Nicholas J., et al. (1999), “Clinical Pharmacokinetics and Pharmacodynamics of Artemether-Lumefantrine:" Clinical Pharmacokinetics, vol. 37, no. 2, pp. 105-25. Crossref, doi:10.2165/00003088199937020-00002.

Xing, Jie, et al. (2006), “A High-Performance Liquid Chromatography/Tandem Mass Spectrometry Method for the Determination of Artemisinin in Rat Plasma." Rapid Communications in Mass Spectrometry, vol. 20, no. 9, pp. 1463-68. Crossref, doi:10.1002/rcm.2467.

Zeng, Mei-Yi, et al. (1996), "Determination of Benflumetol in Human Plasma by Reversed-Phase High-Performance Liquid Chromatography with Ultraviolet Detection.” Journal of Chromatography B: Biomedical Sciences and Applications, vol. 681, no. 2, pp. 299-306. Crossref, doi:10.1016/0378-4347(95)00542-0. 